
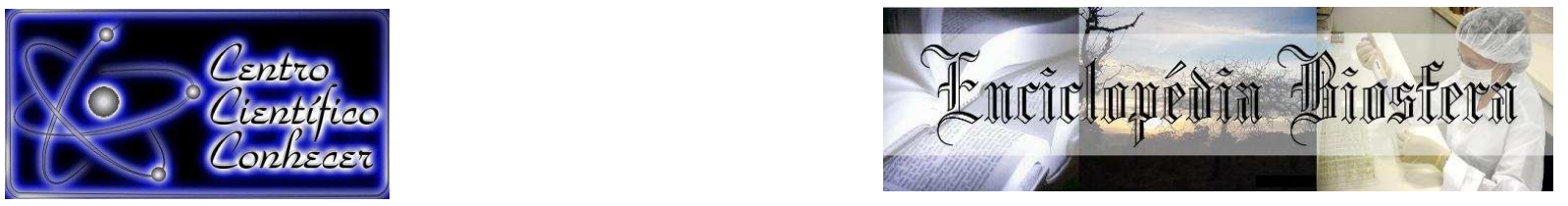

\title{
PERFIL DE ÁCIDOS GRAXOS DE FOLHAS E AMÊNDOAS ORGÂNICAS DE
}

\section{GUARIROBA}

Estevão Julio Walburga Keglevich de Buzin"1; Fábio Venturoli² ; Aniela Pilar Campos de $\mathrm{Melo}^{3}$; Celice Souza Novais ${ }^{4}$.

${ }^{1}$ Pesquisador do Centro Científico Conhecer e Doutorando em Agronomia (UFG), (conhecer@conhecer.org.br) Goiânia, GO - Brasil.

2 Professor da UFG, Goiânia, GO - Brasil.

3 Pesquisadora Doutora em Agronomia do Centro Científico Conhecer,

4 Pesquisadora Doutora em Química do Centro Científico Conhecer,

Recebido em: 08/04/2016 - Aprovado em: 30/05/2016 - Publicado em: 20/06/2016

DOI: 10.18677/Enciclopedia_Biosfera_2016_081

Syagrus oleracea Becc., espécie nativa do Cerrado, pode contribuir com a segurança alimentar, geração de renda para agricultores e para a preservação da espécie, devido aos múltiplos produtos produzidos pela planta. Devido à falta de estudos sobre as propriedades e o aproveitamento de óleos essenciais produzidos por $S$. oleracea, objetivou-se caracterizar o perfil de ácidos graxos de folhas e amêndoas de guariroba presentes em sistema orgânico. As folhas e os frutos maduros, presentes no chão, de guariroba foram coletados de plantas presentes em Jandaia - Goiás sob sistema orgânico. Determinou-se os seguintes atributos: Umidade e Material Volátil, Acidez (\% ácido oléico), Índice de saponificação, Teor de Lipídios e composição/teores de ácidos graxos. Foram encontrados 12 ácidos graxos nas amêndoas e 10 nas folhas. As amêndoas possuem mais ácidos graxos saturados $(87,51 \%)$, enquanto nas folhas há uma tendência de equilíbrio entre saturados $(57,39 \%)$ e insaturados (42,61\%). O índice de acidez dos óleos (\%ácido oléico) obtidos das amêndoas e folhas foram de 20,94\% e 2,13\%, respectivamente. Os óleos de guariroba oriundos de folhas e amêndoas apresentam composição distinta de ácidos graxos. O óleo das folhas é composto majoritariamente por ácido oléico. Já o óleo das amêndoas é formado principalmente por ácidos graxos saturados, como o ácido láurico. Esta diferença de composição influencia no potencial de uso e possíveis aproveitamentos, e conseqüentemente representa mais alternativas de renda para os agricultores.

Palavras-chave: Indústria, Óleos Essenciais, Sub-produto. 


\title{
PROFILE OF FATTY ACIDS OF LEAVES AND ORGANIC ALMONDS OF GUARIROBA
}

\begin{abstract}
Syagrus oleracea Becc., species native to Cerrado, can contribute to food security, income generation for farmers and for the preservation of species, due to the multiple products produced by the plant. Due to the lack of studies on the properties and the use of essential oils produced by $S$. oleracea, the objective of characterizing the fatty acid profile of leaves and kernels guariroba present in organic system. The leaves and the fruits mature, present in the ground, guariroba were collected from plants present in Jandaia-Goiás under organic system. It was determined the following attributes: moisture and volatile material, acidity (\% oleic acid), saponification value, lipid content and composition/fatty acid levels. The fatty acids found 12 almonds and 10 in the leaves. The almonds have more saturated fatty acids (87.51\%), while the leaves there is a tendency to balance between saturated and unsaturated (57.39\%) (42.61\%). The acid value of oils (\% oleic acid) obtained from almonds and leaves were of 20.94 percent and 2.13 percent respectively. Guariroba oils from leaves and almonds feature distinct composition of fatty acids. The oil of the leaves is composed mainly by oleic acid. Already the oil of almonds is formed primarily by saturated fatty acids, like lauric acid. This difference in composition influences the potential use and possible uses, and therefore represents more income alternatives for farmers.
\end{abstract}

Key-words: Industry, Essential Oils, Byproduct.

\section{INTRODUÇÃO}

A palmeira guariroba (Syagrus oleracea Becc.), espécie nativa do Cerrado, está presente na paisagem e na cultura dos agricultores do Centro-Oeste brasileiro. Em razão do desmatamento e adoção de novos sistemas tecnológicos agropecuários os usos culturais da guariroba estão sendo modificados. Esta palmeira demora em média seis anos para que seu palmito atinja o ponto de corte, sendo normalmente realizada a coleta em guarirobas jovens, com aproximadamente três anos. As folhas da guariroba possuem uso forrageiro, para alimentar o gado na época da seca. A guariroba pode contribuir com a segurança alimentar, geração de renda para agricultores e para a preservação da espécie (DIAS, 2012).

A guariroba tem ocorrência principal em fisionomia de cerradão, matas de galeria e matas ciliares. Seus cocos têm forma de um ovo e medem entre quatro e sete centímetros de comprimento pesando entre 30 e 40 gramas em média. Quando maduros estes cocos começam a se desprender e a cair do cacho, apresentando cor verde, verde amarelado ou amarelo. Possui uma casca fina, polpa carnosa e um caroço duro com uma amêndoa interna de cor branca (ANDRADE et al., 2013).

A madeira do tronco da guariroba teve um uso ao proporcionar aos agricultores pioneiros da região Centro-Oeste construir suas casas e outras benfeitorias na propriedade, tais como curral, chiqueiro, pequenas pontes, móveis, 
etc. Este uso ocorria em função da dificuldade de aquisição de madeira beneficiada ou de maquinário para tal fim. O guarirobal pode ser plantado para conter a erosão em locais com declividade acentuada e recompor a mata ciliar de cursos d'água. Existem propriedades onde o guarirobal é usado como Reserva Legal, quando a propriedade é pequena (DIAS et al., 2014).

Os óleos essenciais são misturas de compostos de baixo peso molecular, capazes de gerar sabores e/ou aromas. São extraídos de partes das plantas como frutas, flores, cascas, folhas e raízes. Este termo foi definido no século XVI por Paracelso, médico e alquimista suíço, que determinou que o ingrediente efetivo de uma droga era a sua "quinta essência" (PROBST, 2012).

Para AGGRWAL et al (2013), não há vírus ou bactérias conhecidas que desenvolveram uma imunidade a óleos essenciais por meio de mutação. Os Sesquiterpenos (constituintes químicos de alguns óleos essenciais) possuem a rara capacidade de atravessar a barreira sangue-cérebro, que é um fator crítico na cura de muitas doenças. Existem óleos essenciais, que são quelantes naturais, capazes de carrear toxinas e metais para fora das células. Óleos essenciais estimulam a liberação de endorfinas, proporcionando alivio físico, do desconforto emocional se promovem o sentimento de bem-estar.

Os óleos essenciais são produtos naturais de plantas e possuem uma mistura complexa de componentes, possuindo várias propriedades antimicrobianas (BASSOLÉ \& JULIANI, 2012). Em pesquisa realizada por PROBST (2012), com a avaliação da atividade antibacteriana de óleos essenciais, foi identificado que houve atividade sinérgica com o uso de dois óleos essenciais associados ao antibiótico, com formação de halos aproximadamente quatro vezes maiores àqueles obtidos apenas com o uso do antibiótico.

Além da utilização para a indústria farmacêutica, esta capacidade suscita a utilização de óleos essenciais em outros ramos industriais. Em pesquisa, BERALDO et al. (2013), determinaram que os óleos essenciais de canela e cravoda-índia são mais eficientes que o hipoclorito de sódio na inibição de bactérias. Foi utilizado o método de microdiluição, que determinou a concentração inibitória mínima (CIM) de Óleo Essencial de Canela foi de 0,04\%, para as bactérias Gram positivas, e $<0,02 \%$, para a bactérias Gram negativas. O OE de cravo-da-índia teve CIM de $0,04 \%$ para Salmonella sp., $0,06 \%$ para E. coli e $S$. aureus e $0,08 \%$ para L. monocytogenes. Neste sentido, é possível utilizar os óleos essenciais como princípios ativos de sanitizantes, com os benefícios de serem necessárias menores concentrações para a inibição microbiana e de serem produtos naturais.

Para a indústria de cosméticos, o descobrimento de novos insumos representa uma oportunidade. Este setor é considerado como extremamente competitivo e está associado ao desenvolvimento constante de produtos inovadores. Os consumidores estão cada vez mais exigentes e desejam preferencialmente produtos naturais e confeccionados de forma sustentável. Atualmente existe uma tendência de certificação e selo de origem das matériasprimas utilizadas na indústria de cosméticos (MIGUEL, 2012). Esta certificação tem o objetivo de dar garantias ao consumidor, por exemplo, atestando que a matéria-prima é originada de uma fonte renovável, de um produto orgânico, de um processamento que não polui a natureza. 
A biodiversidade brasileira é rica e o estudo dos óleos essenciais de guariroba, aprofunda o conhecimento das potencialidades desta espécie. Diante do exposto, objetivou-se caracterizar o perfil de ácidos graxos de folhas e amêndoas de guariroba presentes em sistema orgânico.

\section{MATERIAL E MÉTODOS}

\section{Matéria prima}

As folhas e os frutos maduros de guariroba (Syagrus oleracea Becc.) foram coletados de plantas presentes em Jandaia (1703'50.5" S/ 5095'07.4" W $650 \mathrm{~m}$ de altitude) Goiás sob sistema orgânico de produção. Estas plantas apresentavam entre 12 a 15 anos de idade.

Inicialmente, os frutos foram submetidos à secagem ao sol por sete dias. Posteriormente houve beneficiamento por meio de quebra para a retirada de amêndoas do endocarpo do coco. Descartaram-se amêndoas com presença de corós ou rancificadas.

As amêndoas e as folhas foram acondicionadas, separadamente, em sacos plásticos e enviados ao laboratório JLA - Brasil, em Marília, São Paulo. As análises efetuadas consistiram na determinação dos seguintes atributos:

- Umidade e Material Volátil: (AOCS Ca 5a - 40)

- Acidez (\% ácido oléico): (ISSO 662:1998)

- Índice de saponificação: (AOCS CD 3 - 25)

- Teor de Lipídios (IO QU46)

- Composição dos ácidos graxos: caprílico (C8:0), cáprico (C10:0), laúrico (C12:0), mirístico (C14:0), palmítico (C16:0), palmitoleico (C16:1 cis 9), margárico (C17:0), heptadecenoico (C17:1 cis-10), esteárico (C18:0), oléico (C18:1 cis-9), linoléico (C18:2 cis-9-12), linolênico (C:18:3 cis 9-12-15), araquídico (C20:0), eicosenoico (C20:1 cis-9), behénico (C22:0), erúcico (C22: 1 cis-9), lignocérico (C24:0), C18:1 omega 9 trans elaídico, docodienóico (C22:2), capróico (C6:0) - (Cromatografia gasosa - GC-FID).

Os dados obtidos foram submetidos à análise descritiva, por meio da apresentação de médias.

\section{RESULTADOS E DISCUSSÃO}

As folhas e as amêndoas de guariroba apresentaram teores de umidade de $11,50 \%$ e $23,34 \%$, respectivamente. O teor de umidade de amêndoas é variável em função da espécie, beneficiamento de frutos e técnica de extração. Silva et al. (2015) encontraram os seguintes níveis de umidade em amêndoas de arecáceas: Acrocomia intumescens - macaúba (62,2\%), Pinanga kuhlii - pinanga (22,9\%), Ptychosperma macarthurii - palmeira de macarthurii (65,4\%), Syagrus cearensis coco babão (72,5\%), Syagrus coronata - licuri $(74,9 \%)$ e Veitchia merrilli palmeira de manila $(74,4 \%)$. Os autores coletaram os frutos e ocorreu armazenamento a $4^{\circ} \mathrm{C}$ até a execução das análises. 
COIMBRA \& JORGE (2011), em trabalhos de caracterização de amêndoas de guariroba, jerivá (Syagrus romanzoffiana) e macaúba, determinaram o nível de água de amêndoas e polpas separadamente, perfazendo um total de $13,54 \%$ (8,71\% - polpa e 4,83\% - amêndoa). Estas diferenças de teor estão associadas à metodologia de beneficiamento dos frutos, pois os autores submeteram os frutos a secagem em estufa de circulação forçada (40' $)$ por três horas. Desta forma, o beneficiamento dos frutos após a coleta tem efeito direto no teor de umidade das amêndoas.

O extrato etéreo (teor de lipídios) foi maior em amêndoas $(33,09 \%)$, do que em folhas $(7,36 \%)$. Este teor é muito superior a espécies oleaginosas usadas na fabricação de óleos comerciais, tais como: soja (18-20\%), algodão (21\%), canola (24-27\%), amendoim (41,3\%) (Constantino et al., 2014; Silva et al., 2015), porém inferior a amendoim $(44,57 \%)$, avelã $(63,18 \%)$, baru $(41,04 \%)$, castanhade-caju (42,06\%), castanha-do-Brasil (64,94\%), macadâmia $(66,16 \%)$, noz $(65,07 \%)$, pecã $(62,14 \%)$ e pistache $(45,83 \%)$ (FREITAS \& VELOSO, 2010$)$.

O teor de lipídios em sementes e nozes é variável e dependente de fatores abióticos e bióticos (espécies, cultivares e clones). MARO et al. (2012) encontraram teores de extrato etéreo variando de $33,13 \%$ a $64,28 \%$ em genótipos de macadâmia.

O perfil (identificação e quantificação) de ácidos graxos de amêndoas e folhas de guariroba encontra-se na Tabela 1. Verifica-se que a composição lipídica varia em função do órgão da planta de guariroba.

Foram encontrados 12 ácidos graxos nas amêndoas e 10 nas folhas. As amêndoas possuem mais ácidos graxos saturados $(87,51 \%)$, enquanto nas folhas há uma tendência de equilíbrio entre saturados $(57,39 \%)$ e insaturados $(42,61 \%)$. Resultados semelhantes são descritos por NOZAKI et al. (2012) que apontam um teor de $89,2 \%$ de ácidos graxos saturados nas amêndoas de guariroba coletadas no Mato Grosso do Sul.

Os ácidos graxos predominantes nas amêndoas foram o láurico e mirístico. Nas folhas foram o oléico e o araquídico. Não foram detectados nas folhas e amêndoas os ácidos: margárico, heptadecenoico, palmitoleico, erúcico e elaídico.

A composição majoritária de ácido láurico em amêndoas de guariroba é semelhante a outros arecáceas tais como: macaúba (45,44\%), coco babão $(38,11 \%)$, licuri $(44,55 \%)$ e coco (47-50\%) (KAMARIAH et al., 2008) (SILVA et al., 2015). O metabolismo deste ácido graxo proporciona a formação de monolaurina que auxilia na oxidação de ácidos graxos e obtenção de energia. Além disso, este ácido graxo possui aplicação na indústria de alimentos e de produtos de limpeza (CARVALHO E COELHO, 2009). 
Tabela 3.1 Composição de ácidos graxos de amêndoas e folhas de guariroba.

\begin{tabular}{|c|c|c|}
\hline Ácidos graxos & Amêndoas & Folhas \\
\hline \multicolumn{3}{|l|}{ Saturados } \\
\hline caprílico (C8:0) & 11,90 & nd \\
\hline cáprico (C10:0) & 7,25 & 0,75 \\
\hline láurico (C12:0) & 45,80 & 3,91 \\
\hline mirístico (C14:0) & 13,50 & 3,78 \\
\hline palmítico (C16:0) & 4,74 & 9,35 \\
\hline margárico $(\mathrm{C} 17: 0)$ & $\mathrm{Nd}$ & nd \\
\hline heptadecenoico (C17:1 cis-10) & $\mathrm{Nd}$ & nd \\
\hline esteárico (C18:0) & 3,82 & 13,10 \\
\hline araquídico (C20:0) & 0,16 & 13,80 \\
\hline eicosenoico (C20:1 cis-9) & 0,11 & nd \\
\hline behénico (C22:0) & 0,13 & nd \\
\hline lignocérico (C24:0) & 0,10 & 12,70 \\
\hline docodienóico (C22:2) & $\mathrm{Nd}$ & nd \\
\hline \multirow[t]{2}{*}{ capróico (C6:0) } & $\mathrm{Nd}$ & nd \\
\hline & 87,51 & 57,39 \\
\hline \multicolumn{3}{|l|}{ Monoinsaturados } \\
\hline palmitoleico (C16:1 cis 9$)$ & $\mathrm{Nd}$ & nd \\
\hline oléico (C18:1 cis-9) & 10,80 & 30,90 \\
\hline erúcico (C22: 1 cis-9) & $\mathrm{Nd}$ & nd \\
\hline \multirow[t]{2}{*}{ C18:1 omega 9 trans elaídico } & $\mathrm{Nd}$ & nd \\
\hline & 10,80 & 30,9 \\
\hline \multicolumn{3}{|l|}{ Polinsaturados } \\
\hline linoléico (C18:2 cis-9-12) & 1,60 & 8,71 \\
\hline \multirow[t]{2}{*}{ linolênico (C:18:3 cis 9-12-15) } & $\mathrm{Nd}$ & 3,04 \\
\hline & 1,60 & 11,75 \\
\hline
\end{tabular}

nd - não disponível

Os teores de ácido oléico e linoleico presentes nas folhas foram quase três vezes e oito vezes superiores aos presentes em amêndoas, respectivamente (Tabela 1). O ácido oléico é monoinsaturado e considerado majoritário na composição de vários óleos, como: canola $(59,88-60,85 \%)$, baru $(50,4 \%)$, oliva (57,10-59,90\%), milho (34,44-35,68\%), jatobá (31,4\%) girassol $(18,44-28,10 \%)$ (Takemoto et al., 2001; Matuda \& Maria Netto, 2005; Aued-Pimentel et al., 2009; Melo \& Pinheiro, 2012). Já o ácido linoleico é poliinsaturado e considerado um ácido essencial na dieta devido à participação na biossíntese de Omega-3. Perfaz quase $60 \%$ do teor de óleo em sementes de linhaça (Barroso et al., 2014). Possui efeitos variados associados a atividades anticâncer, antinflamatória e de redução da fração lipídica de massa corpórea (LUCATTO et al., 2014).

De acordo com FREITAS e VELOSO (2010), o consumo conjugado de ácidos graxos mono e poliinsaturados favorecem a redução de frações dos 
colesteróis considerados danosos à saúde - LDL (Lipoproteína de Baixa Densidade) e VLDL (de muita baixa densidade).

O índice de acidez dos óleos (\%ácido oléico) obtidos das amêndoas e folhas foram de $20,94 \%$ e $2,13 \%$, respectivamente. Conforme MELLO \& PINHEIRO (2012), a acidez tem relação direta com a natureza da matéria-prima e o processamento. O Regulamento Técnico para óleos e gorduras vegetais da Anvisa determina que o limite de acidez para óleos e gorduras de palma bruto deve ser de $5,0 \mathrm{~g} / 100 \mathrm{~g}$. Desta forma, o óleo das amêndoas está inadequado. Isso pode refletir a inadequabilidade da matéria ou do tipo de processamento. Logo, tais problemáticas devem ser solucionadas para o efetivo aproveitamento deste óleo.

O índice de saponificação consiste na quantidade de hidróxido de potássio necessário para saponificar um grama de amostra de óleo, expresso em miligramas. O índice de saponificação referente ao óleo das folhas de guariroba foi de $167,63 \mathrm{mg} \mathrm{KOH} / \mathrm{g}$. Este valor é inferior ao padrão estabelecido pela Anvisa, para os óleos de: amendoim (187-196 mg KOH/g), arroz (181-189 mg KOH/g), canola (182-193 $\mathrm{mg} \mathrm{KOH} / \mathrm{g}$ ), girassol (188-194 mg KOH/g), milho (187-195 mg $\mathrm{KOH} / \mathrm{g}$ ), soja (189-195 mg KOH/g) e uva (188-194 mg KOH/g). Desta forma, para a produção de sabões oriundos de óleos de guariroba são necessárias menores quantidades de $\mathrm{KOH}$, possibilitando economia de reagentes no processo.

O índice de saponificação de óleos oriundos das amêndoas foi de $192,75 \mathrm{mg} \mathrm{KOH} / \mathrm{g}$. Este índice é inferior ao relatado por Nozaki et al. (2012) de $278 \mathrm{mg} \mathrm{KOH} / \mathrm{g}$ e em relação à outros óleos de amêndoas tropicais, tais como: coco de babaçu (245-256 mg KOH/g), coco (248-265 mg KOH/g), palma (190-209 $\mathrm{mg} \mathrm{KOH} / \mathrm{g}$ ) e palmiste $(230-254 \mathrm{mg} \mathrm{KOH} / \mathrm{g})$. Portanto, a produção de sabões a partir de óleos de amêndoas também pode ser favorecida pela menor exigência de $\mathrm{KOH}$.

No cultivo da guariroba o principal produto explorado consiste no palmito amargo. No entanto, é possível também o aproveitamento das amêndoas, polpa do fruto, o óleo do coró (medicinal) e as folhas para a alimentação do gado no período seco (DIAS et al., 2014). Desta forma, a identificação de mais um potencial para folhas e amêndoas representa mais um fator de geração de renda aos produtores.

Desta forma, é imprescindível a realização de mais estudos associados a métodos de extração, conservação e utilização de óleos de guariroba. Portanto, deve-se aperfeiçoar e simplificar tal processo juntamente com maior conhecimento a respeito da conservação do óleo obtido.

\section{CONCLUSÃO}

Os óleos de guariroba oriundos de folhas e amêndoas apresentam composição distinta de ácidos graxos.

O óleo das folhas é composto majoritariamente por ácido oléico. Já o óleo das amêndoas é formado principalmente por ácidos graxos saturados, como o ácido láurico. Esta diferença de composição influencia no potencial de uso e possíveis aproveitamentos. 


\section{REFERÊNCIAS}

AGGARWAL S., AGARWAL S., JALHAN S. Essential oils as novel human skin penetration enhacer for transdermal drug delivery: a review. International Journal of Pharma and Bio Sciences, v. 4, n. 1, p. 857-868, 2013.

AUED-PIMENTEL, S.; KUMAGAI, E. E.; KUS, M. M. M.; CARUSO, M. S. F.; TAVARES, M.; ZENEBON, O. Ácidos graxos trans em óleos vegetais refinados poli-insaturados comercializados no estado de São Paulo, Brasil. Ciência Tecnologia de Alimentos, v. 29, n. 3, p. 646-651, 2009.

BARROSO, A. K. M.; TORRES, A. G.; CASTELO-BRANCO, V. N.; FERREIRA, A.; FINOTELLI, P. V.; FREITAS, S. P.; ROCHA-LEÃO, M. H. M. Linhaça marrom e dourada: propriedades químicas e funcionais das sementes e dos óleos prensados a frio. Ciência Rural, v. 44, n. 1, p. 181-187, 2014.

BASSOLÉ, N; JULIANI, H.R. Essential Oils in Combination and Their Antimicrobial Properties. Molecules, v. 17, n. 4, p. 3989-4006, 2012.

CARVALHO, M. R. A. C. G.; COELHO, N. R. A. Leite de coco: aplicações funcionais e tecnológicas. Estudos, v. 36, n. 5/6, p. 851-865, 2009.

COIMBRA, M. C.; JORGE, N. Proximate composition of guariroba (Syagrus oleracea), jerivá (Syagrus romanzoffiana) and macauba (Acrocomia aculeata) palm fruis. Food Research International, v. 44, p. 2129-2142, 2011.

CONSTANTINO, A. F.; LACERDA JR., V.; SANTOS, R. B.; GRECO, S. J.; SILVA, R. C.; NETO, A. C.; BARBOSA, L. L.; CASTRO, E. V. R.; FREITAS, J. C. C. Análise de teor e da qualidade dos lipídeos presentes em sementes de oleaginosas por RMN de baixo campo. Química Nova, v. 37, n. 1, p. 10-17, 2014.

DIAS, J. A. Cadeia produtiva do óleo de Guariroba (Syagrus oleracea Becc.): geração de renda para agricultores familiares e promoção da agrobiodiversidade, Buriti de Goiás (GO). 2012. 148 f. Dissertação (Dissertação em Ciências Agronômicas) - Universidade de São Paulo/Faculdade de Filosofia, Letras e Ciências Humanas, Botucatu, 2012.

DIAS, J. E.; LAUREANO, L. C.; MING, L. C. Cadeia produtiva do óleo de amêndoas de gueroba (Syagrus oleracea): geração de renda para agricultores familiares e promoção da agrobiodiversidade. Revista Brasileira de Agroecologia, v. 9, n. 1, p. 122-133, 2014.

FREITAS, J. B.; NAVES, M. M. V. Chemical composition of nuts and edible seeds and their relation to nutrition and health. Revista de Nutrição, v. 23, n. 2, p. 269279, 2010. 
KAMARIAH, L.; AZMI, A.; ROSMAWATI, A.; WAI CHING, M. G.; AZLINA, M. D.; SIVAPRAGASAM, A.; TAN, C. P.; LAI, O. M. Physico-chemical and quality characteristics of virgin coconut oil - A Malaysian survey. Journal Tropical Agriculture and Food Science, v. 36, n. 2, p. 1-10, 2008.

LUCATTO, J. N.; MENDONÇA, S. N. T. G.; DRUNKLER, D. A. Ácido linoleico conjugado: estrutura química, efeitos sobre a saúde humana e análise em lácteos. Revista do Instituto Laticínios Cândido Tostes, v. 69, n. 3, p. 199-211, 2014.

MATUDA, T. G.; MARIA NETTO, F. Caracterização química parcial da semente de jatobá-do-cerrado (Hymenaea stigonocarpa Mart.). Ciência Tecnologia Alimentar, v. 25, n. 2, p. 353-357, 2005.

MARO, L. A. C.; PIO, R.; PENONI, E. S.; OLIVEIRA, M. C.; PRATES, F. C.; LIMA, L. C. O.; CARDOSO, M. . Caracterização química e perfil de ácidos graxos em cultivares de nogueira-macadâmia. Ciência Rural, v. 42, n. 12, p. 2166-2171, 2012.

MELLO, L. D.; PINHEIRO, M. F. Aspectos físico-químicos de azeites de oliva e de folhas de oliveira provenientes de cultivares do RS, Brasil. Alimentos e Nutrição, v. 23, n. 4, p.537-548, 2012.

MIGUEL, L. M. A biodiversidade na indústria de cosméticos: contexto internacional e mercado brasileiro. 2012. 273 f. Tese (Tese em Agronomia) Universidade de São Paulo/Faculdade de Filosofia, Letras e Ciências Humanas, São Paulo, 2012.

NOZAKI, V. T.; MUNHOZ, C. L.; GUIMARÃES, R. C. A.; HIANE, P. A.; ANDREU, M. P.; VIANA, L. H.; MACEDO, M. L. R. Perfil lipídico da polpa e amêndoa da guarirova. Ciência Rural, v. 42, n. 8, p. 1518-1523, 2012.

PROBST; I. S. Atividade antibacteriana de óleos essenciais e avaliação do potencial sinérgico. 2012. 155 f. Dissertação (Dissertação em Biologia Geral) Universidade Estadual Paulista “Júlio de Mesquita Filho”, Botucatu, 2012.

SILVA, R. B.; SILVA-JÚNIOR, E. V.; RODRIGUES, L. C.; ANDRADE, L. H. C.; SILVA, S. I. D. A.; HARAND, W.; OLIVEIRA, A. F. M. A comparative study of nutritional composition and potential use of some underutilized tropical fruits of Arecaceae. Anais da Academia Brasileira de Ciências, v. 87, n. 3, p. 17011709, 2015.

SOUZA, F.G.; RODRIGUES, F.M.; RODRIGUES, L.G.S.M. Extração artesanal e caracterização do óleo de Macaúba (Acrocomia aculeata) em dois estágios de maturação, Enciclopédia Biosfera, v.9, n.16, p. 1188-1195, 2013.

TAKEMOTO, E.; OKADA, I. A.; GARBELOTTI, M. L.; TAVARES, M.; AUEDPIMENTEL, S. Composição química da semente e óleo de baru (Dipteryx alata 
Vog.) nativo do município de Pirenópolis, Estado de Goiás. Revista Instituto Adolfo Lutz, v. 60, n. 2, p. 113-117, 2001. 